\title{
AIDS-Related Human Papillomavirus Infection
}

National Cancer Institute

\section{Source}

National Cancer Institute. AIDS-Related Human Papillomavirus Infection. NCI Thesaurus.

Code C103296.

An opportunistic infection caused by the human papillomavirus in a patient with AIDS. 